\title{
Desenvolvimento de amendoim submetido a adubação fosfatada e potássica e diferentes espaçamento entre plantas
}

Leandro Alves Pinto ${ }^{1}$, Antonio Alves Pinto ${ }^{2}$, Marcos Silva Tavares ${ }^{1}$, Felipe Thomaz da Camara ${ }^{1}$, Luis Fernando Vieira da Silva ${ }^{2}$

${ }^{1}$ Universidade Federal do Cariri - UFCA, CE. ${ }^{2}$ Universidade Estadual Paulista - UNESP, SP. E-mail: leandroalvespinto96@gmail.com

\section{Resumo}

Objetivou-se avaliar o cultivo de amendoim em função da adubação fosfatada e potássica na semeadura e do espaçamento entre plantas, em regime de sequeiro e irrigação por gotejamento no Cariri-CE. Foi utilizado o delineamento experimental em bloco ao acaso, em esquema de parcela subdividida com quatro repetições. As parcelas foram constituídas pelas doses de adubação com $\mathrm{K}$ e $\mathrm{P}$ de semeadura $(0,50,100 \mathrm{e}$ $150 \%$ da dose recomendada) e as subparcelas por dois espaçamentos entre plantas (10 e $20 \mathrm{~cm}$ ). As variáveis avaliadas foram população inicial, população final, altura da planta, massa de grãos por planta, número de vagens por planta, massa de vagens por planta, massa de grãos por vagens, massa de1000 grãos e massa de 100 vagens, produtividade de vagens, produtividade de grãos e porcentagem de grãos não comerciais. Os resultados demonstraram que o sistema sequeiro e irrigação influenciaram na produção do amendoim e a adubação no número vagens e a massa de vagens por planta foram significativas obtendo o ponto de máxima nas doses de 82,58 e $80,37 \%$, respectivamente. 0 espaçamento de $20 \mathrm{~cm}$ ampliou a produtividade de grãos por plantas e a massa de 1000 grãos em $10,77 \%$ e $14,8 \%$ respectivamente.

Palavras-chave: arachis hypogaea l.; fósforo; densidade.

\section{Development of peanuts subjected to phosphate and potassium fertilization and different plant spacing}

\begin{abstract}
The objective of this study was to evaluate the cultivation of peanuts as a function of phosphate and potassium fertilization in sowing and spacing between plants, in dry land and drip irrigation in Cariri-CE. A randomized block design was used in a split-plot scheme with four replications. The plots consisted of the fertilization doses with $\mathrm{K}$ and $\mathrm{P}$ of sowing $(0,50,100$ and $150 \%$ of the recommended dose) and the subplots by two spacings between plants $(10$ and $20 \mathrm{~cm})$. The variables evaluated were initial population, final population, plant height, grain mass per plant, number of pods per plant, pod mass per plant, grain mass per pods, mass of 1000 grains and mass of 100 pods, pod yield, grain yield and percentage of noncommercial grains. The results showed that the dry sequeiro and irrigation system influenced the production of peanuts and fertilization in the number of pods and the mass of pods per plant were significant, obtaining the maximum point at doses of 82.58 and $80.37 \%$, respectively. The spacing of $20 \mathrm{~cm}$ increased grain yield by plants and the mass of 1000 grains by $10.77 \%$ and $14.8 \%$, respectively.
\end{abstract}

Keywords: arachis hypogaea l.; phosphor; density.

\section{Introdução}

O amendoim (Arachis hypogaea L.) é uma das oleaginosas de maior relevância nos âmbitos mundial e nacional (FERREIRA, 2014). No Brasil a produção total da safra $2018 / 19$ foi de 434,5 milhões de toneladas em uma área de 146,6 mil hectares, sendo que as maiores áreas cultivadas com amendoim estão principalmente nas regiões Sudeste e Sul com aproximadamente 142,8 mil hectares, juntas essas duas regiões produziram cerca de 426,2 milhões de toneladas de amendoim o Estado de São Paulo foi responsável 
por cerca de 93,5\% da produção nacional, tornando-se o maior produtor (CONAB, 2019).

No Nordeste, as maiores áreas cultivadas concentram-se principalmente nos estados da Bahia, Paraíba e Ceará, mas o Estado da Bahia se destaca como o maior produtor, responsável por cerca de $73,6 \%$ da produção da Região Nordeste, No entanto nesses estados os principais fatores limitantes para a produção de amendoim são as condições climáticas e o baixo uso de adubação de semeadura (CONAB, 2019).

$A$ adubação é um fator importante pós atua diretamente no desenvolvimento e produtividade das plantas. Assim sendo, o fornecimento adequado e balanceado de nutrientes é essencial para favorecer o aumento significativos da cultura. O fósforo é crucial no metabolismo das plantas, uma vez que atua na transferência de energia na célula, na taxa respiratória, fotossíntese, compõe estruturas de ácidos nucléicos, genes, cromossomos assim como diversas coenzimas (GRANT, 2001). Desta forma, este nutriente é importante no crescimento inicial das raízes e tem função básica no desenvolvimento das sementes (MARQUES, 2014). O potássio também tem alto grau de importância no desenvolvimento vegetal, pois é um controlador dos movimentos estomáticos e ativador metabólico essencial para formação de proteínas, mesmo não possuindo função estrutural ou metabólica (HESS, 2015).

No planejamento da produção a adubação é um importante fator a ser considerado, porém, a escolha do espaçamento adequado para otimizar o uso da área de produção sem causar adensamento excessivo nas cultivares de porte ereto é outro fator a ser levado em consideração. Conforme Heid et al.
(2016), o espaçamento é uma importante estratégia de produção por proporcionar melhor aproveitamento de fatores que estão diretamente relacionados com a produção do amendoim como, água, luz, solo, nutrientes e etc.

$\mathrm{O}$ amendoim é cultivado em condições de sequeiro, principalmente em regiões com chuvas irregulares, como o nordeste do Brasil ficando sujeitas a elevados riscos causados pelas variações de clima, incluindo a instabilidade de chuvas, ocasionando baixas produções (SANTOS et al., 2012).

Nesse sentido, objetivou-se avaliar o desenvolvimento da cultura do amendoim em função da adubação fosfatada e potássica na semeadura e espaçamento entre plantas em regime de sequeiro e irrigação complementar no Cariri-CE.

\section{Material e Métodos}

O experimento foi desenvolvido de março a junho de 2017, na área experimental do Centro de Ciências Agrária e da Biodiversidade, da Universidade Federal do Cariri (UFCA), Crato- CE, com coordenadas geográficas $39^{\circ} 22^{\prime} 05^{\prime \prime} \mathrm{W}$, $7^{\circ} 14^{\prime} 49^{\prime \prime S}$ e 413 metros de altitude. O clima da região se caracteriza como tropical úmido com estação de seca (ALVARES et al., 2013), regime pluviométrico de 700 a $1000 \mathrm{~mm} \mathrm{ano}{ }^{-1} \mathrm{e}$ temperatura com média de $27^{\circ} \mathrm{C}$ anual.

Com uso de um pluviômetro foi mensurado a distribuição das chuvas no período de condução do experimento, a instalação do aparelho foi realizada ao lado da área, os dados obtidos diariamente conforme a Figura 1.

Figura 1. Dados de Precipitação pluviométrica na área experimental durante os meses de março a maio (2017) período da semeadura ao início da maturação.

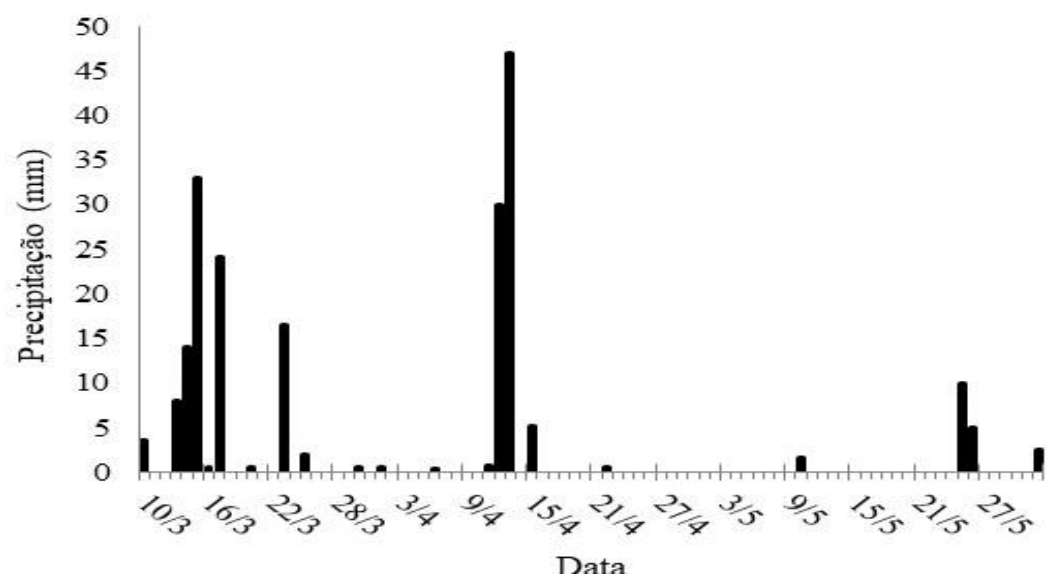


De acordo com classificação do mapa de solos da FUNCEME (2012), o solo da área experimental é classificado como Argissolo Vermelho-Amarelo de relevo suave ondulado. Os resultados da análise de solo foram expressos na Tabela 1.

Tabela 1. Resultados referentes a análise de solo.

\begin{tabular}{|c|c|c|c|c|c|c|c|c|c|c|c|c|}
\hline \multicolumn{13}{|c|}{ ANALISE DO SOLO } \\
\hline $\mathrm{cm}$ & \multicolumn{3}{|c|}{$\mathrm{g} \mathrm{kg}^{-1}$} & & $\mathrm{Mg} / \mathrm{dm}^{3}$ & \multicolumn{6}{|c|}{$\mathrm{mmol}_{\mathrm{c}} \mathrm{dm}^{-3}$} & $\%$ \\
\hline Amostra & Areia & Silte & Argila & $\begin{array}{c}\mathrm{pH} \\
\left(\mathrm{H}_{2} \mathrm{O}\right)\end{array}$ & $P$ (melich & $\mathrm{K}$ & $\mathrm{Ca}$ & $\mathrm{Mg}$ & $\mathrm{Al}$ & $\begin{array}{c}\mathrm{H}+ \\
\mathrm{Al}\end{array}$ & CTC & V \\
\hline $0-20$ & 873 & 33 & 94 & 5,7 & 5,6 & 1,90 & 15,4 & 5,0 & 0,0 & 10,4 & 33,0 & 68,5 \\
\hline
\end{tabular}

Conduziu-se dois experimentos simultâneos em áreas próximas. O primeiro experimento foi conduzido em condição de sequeiro, enquanto que o segundo experimento foi realizado com irrigação localizada através de fitas gotejadoras dispostas entre as fileiras duplas. Foi aplicada lâmina diária de $7,5 \mathrm{~mm}$ nos dias em que não houve precipitação pluviométrica, visando suprir a demanda hídrica da cultura do amendoim devido à distribuição irregular das chuvas na região.

Foi utilizado delineamento experimental em blocos ao acaso, com quatro repetições, em esquema de parcela subdividida. As parcelas foram constituídas pelas doses de adubação de semeadura $(0,50,100$ e $150 \%$ da dose recomendada) e as subparcelas por dois espaçamentos entre plantas $(10$ e $20 \mathrm{~cm})$. As subparcelas constaram de quatro fileiras duplas com três metros de comprimento e com espaçamento de 0,6 m entre as duplas e de $0,3 \mathrm{~m}$ entre as fileiras simples. As duas fileiras centrais com um metro de comprimento foram utilizadas como área útil para análise final do amendoim.

A cultivar utilizada foi a BR-1, tolerante a seca e ciclo de 90 dias após a emergência, apresenta rendimento médio de $1.700 \mathrm{~kg} / \mathrm{ha}$ de amendoim em vagens em regime de sequeiro e $3.500 \mathrm{~kg} /$ ha sob irrigação (SANTOS, 2000).

Em virtude da cultura utilizada realizar simbiose com bactérias do gênero Rhizobium, não foi realizada adubação nitrogenada. A suplementação de fósforo e potássio foram realizadas com base na análise de solo e nas exigências da cultura, utilizando-se a recomendação feita pela Embrapa (2014). Utilizou-se como dose ideal (100\%) as quantias de $80 \mathrm{~kg} \mathrm{ha}^{-1}$ de $\mathrm{P}_{2} \mathrm{O}_{5}$ (444 $\mathrm{kg} \mathrm{ha}^{-1}$ de superfosfato simples) e $40 \mathrm{~kg} \mathrm{ha}^{-1}$ de $\mathrm{K}_{2} \mathrm{O}\left(67 \mathrm{~kg} \mathrm{ha}^{-1}\right.$ de cloreto de potássio). As demais doses estudadas foram:
40 e $120 \mathrm{~kg} \mathrm{ha}^{-1}$ de $\mathrm{P}_{2} \mathrm{O}_{5}\left(222\right.$ e $666 \mathrm{~kg} \mathrm{ha}^{-1}$ de superfosfato simples), 20 e $80 \mathrm{~kg} \mathrm{ha}^{-1}$ de $\mathrm{K}_{2} \mathrm{O}$ (33,3 e $133 \mathrm{~kg} \mathrm{ha}^{-1}$ de cloreto de potássio).

No dia 10 de março de 2017 foram realizadas simultaneamente, a semeadura e adubação, colocando-se 5 e 10 sementes por metro, de forma manual, para os espaçamentos de 20 e $10 \mathrm{~cm}$ entre plantas, respectivamente. Durante o desenvolvimento da cultura foram realizados alguns tratos culturais como capinas manuais e a amontoa no florescimento.

A colheita foi realizada em junho de 2017, mantendo-se as plantas com as vagens voltadas para cima por cinco dias no campo para secagem.

Durante a condução do estudo, foi avaliada a população inicial, (contagem da quantidade de plantas emergidas em um metro de fileira, com os dados foram convertidos para plantas ha $^{-1}$ ), aos 21 dias após a semeadura (DAS). Pelo mesmo método a população final na colheita.

Após a colheita foi avaliada a altura de plantas (diferença entre a superfície do solo e o ápice da planta), número e massa de vagens e de grãos por planta (Obtida a partir da contagem e pesagem de todas as vagens e grãos da parcela útil e divisão pelo número de plantas contidas da parcela útil), número e massa de grãos por vagem (a partir da separação dos grãos das vagens, realizando a contagem e pesagem dos grãos e dividido pelo número de vagens contidas na parcela útil), a massa de cem grãos e cem vagens (Determinada pela pesagem de cem vagens e grãos), produtividade de vagens e de grãos (extrapolação dos resultados de massa de vagens e de grãos da área útil para $\mathrm{kg} \mathrm{há}^{-1}$ ) e porcentagem de grãos não comerciais (a partir da relação entre a massa de grãos ruins e de grãos comerciais, expressando os dados em porcentagem). 
Os dados foram submetidos à análise de variância, em seguida aplicado o teste de Tukey $(p<0,05)$ para o espaçamento e análise de regressão para as doses de adubação. Utilizando o software Sisvar (FERREIRA, 2011).

\section{Resultados e Discussão}

De acordo com os dados da Tabela 2, os fatores não apresentaram interações significativas, permitindo a avalição dos fatores adubação e espaçamento de forma individual.
Na Tabela 2, o fator espaçamento entre plantas não apresentou diferença significativa para as variáveis avaliadas, exceto para a população final no sistema de sequeiro $(p<0,01)$. Assunção e Escobedo (2009), relataram que tais resultados independem da densidade uma vez que as plantas estão nas mesmas condições, em casos onde ocorram restrições hídricas, fator limitante para o crescimento das plantas, essas independem da densidade.

Tabela 2. Síntese da análise de variância, análise de regressão e do teste de médias para as variáveis população inicial, população final e altura da planta.

\begin{tabular}{|c|c|c|c|c|c|c|c|}
\hline \multicolumn{8}{|c|}{ Valores de F } \\
\hline \multirow{2}{*}{ Fontes de Variação } & \multicolumn{3}{|c|}{ População Inicial } & \multicolumn{2}{|c|}{ População Final } & \multicolumn{2}{|c|}{ Altura } \\
\hline & GL & Sequeiro & Gotejo & Sequeiro & Gotejo & Sequeiro & Gotejo \\
\hline Bloco & 3 & $1,02^{\mathrm{ns}}$ & $1,84^{\mathrm{ns}}$ & $3,19^{\mathrm{ns}}$ & $0,59^{\mathrm{ns}}$ & $0,07^{\mathrm{ns}}$ & $1,68^{\text {ns }}$ \\
\hline Adubação (A) & 3 & $3,15^{\mathrm{ns}}$ & $22,19^{\mathrm{ns}}$ & $3,17^{*}$ & $1,47^{\mathrm{ns}}$ & $0,04^{\mathrm{ns}}$ & $0,25^{\mathrm{ns}}$ \\
\hline Resíduo 1 & 9 & - & - & - & - & - & - \\
\hline Espaçamento (E) & 1 & $0,95^{\mathrm{ns}}$ & $3,43^{\mathrm{ns}}$ & $12,50 * *$ & $3,73^{\mathrm{ns}}$ & $0,86^{\mathrm{ns}}$ & $0,10^{\mathrm{ns}}$ \\
\hline$A^{*} E$ & 3 & $0,58^{\mathrm{ns}}$ & $0,02^{\text {ns }}$ & $3,55^{\mathrm{ns}}$ & $0,48^{\mathrm{ns}}$ & $1,98^{\mathrm{ns}}$ & $0,64^{\mathrm{ns}}$ \\
\hline Resíduo 2 & 12 & - & - & - & - & - & - \\
\hline CV1 (\%) & - & 20,25 & 13,40 & 28,67 & 39,32 & 19,54 & 14,70 \\
\hline CV2 (\%) & - & 37,14 & 46,90 & 22,46 & 41,11 & 10,673 & 14,28 \\
\hline Média geral & - & 103125,00 & 110763,96 & 76736,15 & 81597,37 & 35,75 & 62,75 \\
\hline \multicolumn{8}{|c|}{ Análise de Regressão para Adubação } \\
\hline Linear & & $7,95^{\mathrm{ns}}$ & $46,40^{\mathrm{ns}}$ & $8,04^{*}$ & $0,17^{\mathrm{ns}}$ & $0,02^{\text {ns }}$ & $0,17^{\mathrm{ns}}$ \\
\hline Quadrática & & $0,01^{\text {ns }}$ & $0,44^{\mathrm{ns}}$ & $0,65^{\mathrm{ns}}$ & $2,73^{\mathrm{ns}}$ & $0,02^{\mathrm{ns}}$ & $0,45^{\mathrm{ns}}$ \\
\hline \multicolumn{8}{|c|}{ Teste de Médias } \\
\hline Espaçamento & & \multicolumn{4}{|c|}{------------- Plantas ha' ${ }^{-1}$----------- } & \multicolumn{2}{|c|}{------ cm ------ } \\
\hline 10 & & $109722,18 \mathrm{a}$ & $127777,81 \mathrm{a}$ & $87500,00 \mathrm{a}$ & $93055,62 \mathrm{a}$ & 36,37 a & $63,25 \mathrm{a}$ \\
\hline 20 & & 96527,81 a & 93750,12 a & $65972,31 \mathrm{~b}$ & 70139,12 a & 35,12 a & $62,25 \mathrm{a}$ \\
\hline
\end{tabular}

Nota: Médias seguidas pela mesma letra minúscula na coluna não diferem entre si pelo teste de Tukey a $5 \%$ de probabilidade.**: significativo $(P<0,01)$; $^{*}$ : significativo $(P<0,05)$; ns: não significativo; CV\%: coeficiente de variação.

De acordo com Gomes (2009), os valores do coeficiente de variação foram médios (10 e $20 \%$ ), altos (20 e $30 \%$ ) e muito altos (>30\%), para todos os fatores estudados. Conforme relatado por Artur et al. (2014), essa variação esta sujeitos a vários fatores não controlados, principalmente os relacionados ao solo, que apresentam grande heterogeneidade devido aos atributos químicos do solo que apresentaram grande variabilidade espacialmente.

Nota-se que no fator adubação não ocorreu diferença significativa para maioria das variáveis analisadas, exceto para a população inicial no sistema de gotejo e população final em sistema de sequeiro que obtiveram significância $(p<0,01)$ e $(p<0,05)$, respectivamente. Na análise de regressão (Tabela 2) a população final no sistema de sequeiro obtive diferença significativa $(p<0,05)$, com modelos de regressão lineares. 0 aumento das doses de adubação em semeadura proporcionou diminuição da população (Figura 2), tais resultados podem ter ocorrido devido as propriedades físicas dos adubos que absorvem para si a umidade do meio externo, as plantas menos resistentes por não terem umidade suficiente para se desenvolverem acabam morrendo. Os resultados diferem dos observados por Costa et al. (2017) ao estudarem a resposta do cultivar BRS151L7 em função da adubação de semeadura, não obtendo diferença significativa para as populações inicial e final, porém o experimento com conduzido sob irrigação, sistema no qual também foi observado diferença significativa neste trabalho. 
Figura 2. Análise de regressão para população final de plantas de amendoinzeiro sob adubação de semeadura em regime de sequeiro.

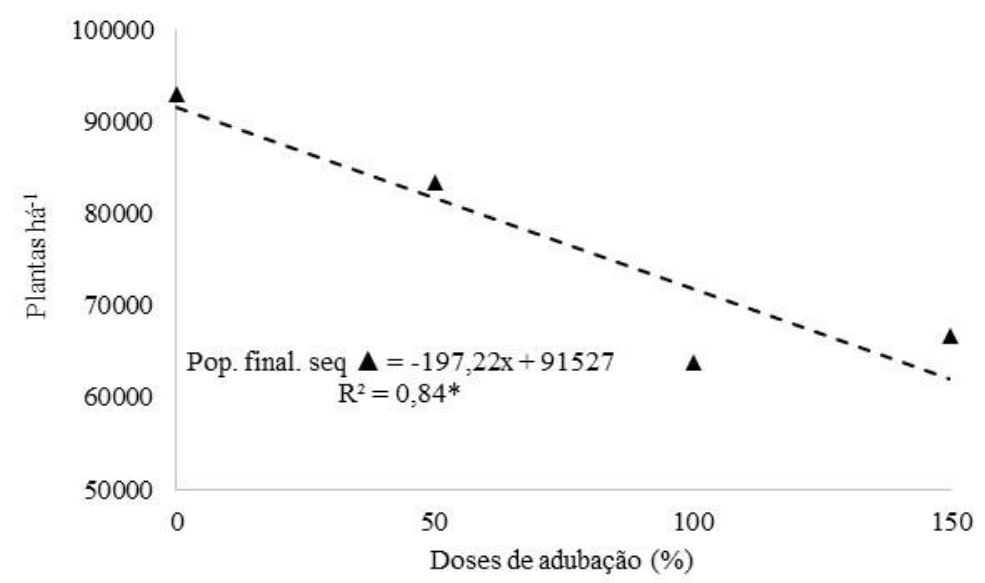

Na Tabela 3, a adubação não apresentou diferença significativa para todas as variáveis analisadas. Costa et al. (2017), obtiveram resultados similares aos desse trabalha para 0 número de vagens por planta, para os tratamentos com e sem NPK na semeadura.

O espaçamento não apresentou significância para nem uma das variáveis analisadas. Os mesmos resultados não foram observados por Silveira et al. (2013), ao estudarem os componentes de produção de amendoim em diferentes épocas de semeadura e densidades de plantas observaram maior número de vagens por planta na menor população de plantas.

Tabela 3. Síntese da análise de variância, análise de regressão e do teste de médias para as variáveis Massa de grãos por planta (MG/P), número de vagens por planta (NV/P), Massa de vagens por planta (MV/P).

\begin{tabular}{|c|c|c|c|c|c|c|c|}
\hline \multicolumn{8}{|c|}{ Valores de F } \\
\hline \multirow{2}{*}{ Fontes de Variação } & \multicolumn{3}{|c|}{$\mathrm{NV} / \mathrm{P}$} & \multicolumn{2}{|c|}{$\mathrm{MV} / \mathrm{P}$} & \multicolumn{2}{|c|}{$\mathrm{MG} / \mathrm{P}$} \\
\hline & GL & Sequeiro & Gotejo & Sequeiro & Gotejo & Sequeiro & Gotejo \\
\hline Bloco & 3 & $1,55^{\mathrm{ns}}$ & $0,52^{\mathrm{ns}}$ & $1,98^{\mathrm{ns}}$ & $1,56^{\mathrm{ns}}$ & $2,67^{\mathrm{ns}}$ & 4,15 \\
\hline Adubação (A) & 3 & $0,27^{\mathrm{ns}}$ & $3,12^{\mathrm{ns}}$ & $0,61^{\mathrm{ns}}$ & $3,47^{\mathrm{ns}}$ & $1,47^{\mathrm{ns}}$ & $0,40^{\mathrm{ns}}$ \\
\hline Resíduo 1 & 9 & - & - & - & - & - & - \\
\hline Espaçamento (E) & 1 & $0,31^{\mathrm{ns}}$ & $1,64^{\mathrm{ns}}$ & $0,63^{n s}$ & $2,57^{\mathrm{ns}}$ & $0,32^{\mathrm{ns}}$ & $0,01^{\mathrm{ns}}$ \\
\hline$A^{*} E$ & 6 & $1,24^{\mathrm{ns}}$ & $0,96^{\mathrm{ns}}$ & $1,21^{\mathrm{ns}}$ & $0,73^{n s}$ & $1,12^{\mathrm{ns}}$ & $3,89^{n s}$ \\
\hline Resíduo 2 & 12 & - & - & - & - & - & - \\
\hline CV1 (\%) & - & 55,96 & 26,20 & 55,12 & 25,71 & 48,93 & 19,74 \\
\hline CV2 (\%) & - & 47,38 & 34,20 & 41,02 & 32,63 & 52,80 & 14,49 \\
\hline Média geral & - & 12,30 & 24,64 & 10,68 & 29,39 & 0,2588 & 0,63 \\
\hline \multicolumn{8}{|c|}{ Análise de Regressão para Adubação } \\
\hline Linear & & $0,43^{\mathrm{ns}}$ & $1,15^{\mathrm{ns}}$ & $0,58^{\mathrm{ns}}$ & $0,97^{\mathrm{ns}}$ & $1,02^{\mathrm{ns}}$ & $0,79^{\mathrm{ns}}$ \\
\hline Quadrática & & $0,03^{\mathrm{ns}}$ & $6,61^{*}$ & $0,97^{\mathrm{ns}}$ & $9,36^{*}$ & $3,12^{\mathrm{ns}}$ & $0,00^{\mathrm{ns}}$ \\
\hline \multicolumn{8}{|c|}{ Teste de Médias } \\
\hline Espaçamento & & $-----u$ & ---- & & ----------- & ------------ & \\
\hline 10 & & $11,73 \mathrm{a}$ & $22,73 \mathrm{a}$ & $10,07 \mathrm{a}$ & $26,67 \mathrm{a}$ & $0,23 a$ & $0,62 \mathrm{a}$ \\
\hline 20 & & $12,87 \mathrm{a}$ & $26,55 \mathrm{a}$ & 11,30 a & $32,11 \mathrm{a}$ & $0,26 \mathrm{a}$ & $0,63 \mathrm{a}$ \\
\hline
\end{tabular}

Nota: Médias seguidas pela mesma letra minúscula na coluna não diferem entre si pelo teste de Tukey a $5 \%$ de probabilidade.**: significativo $(P<0,01)$; *: significativo $(P<0,05)$; ns: não significativo; $C V \%$ : coeficiente de variação.

$\mathrm{Na}$ análise de regressão (Tabela 3) o número de vagens por planta no sistema de gotejo obtive diferença significativa $(p<0,05)$ em função das doses de adubação, com modelo de regressão quadrática (Figura 3 ). 0 ponto de máximo foi observado com a aplicação de $82,5 \%$ 
da dose recomendada produzindo 28,24 vagens por planta, resultado associado ao afirmado por Tasso Júnior et al. (2004) que apesar da cultura do amendoim não ser muito exigente em nutrientes, a adubação aumenta, quando aplicado corretamente, a qualidade e a quantidade de vagens.

Figura 3. Análise de regressão para as variáveis número de vagens por planta e massa de vagens por planta.

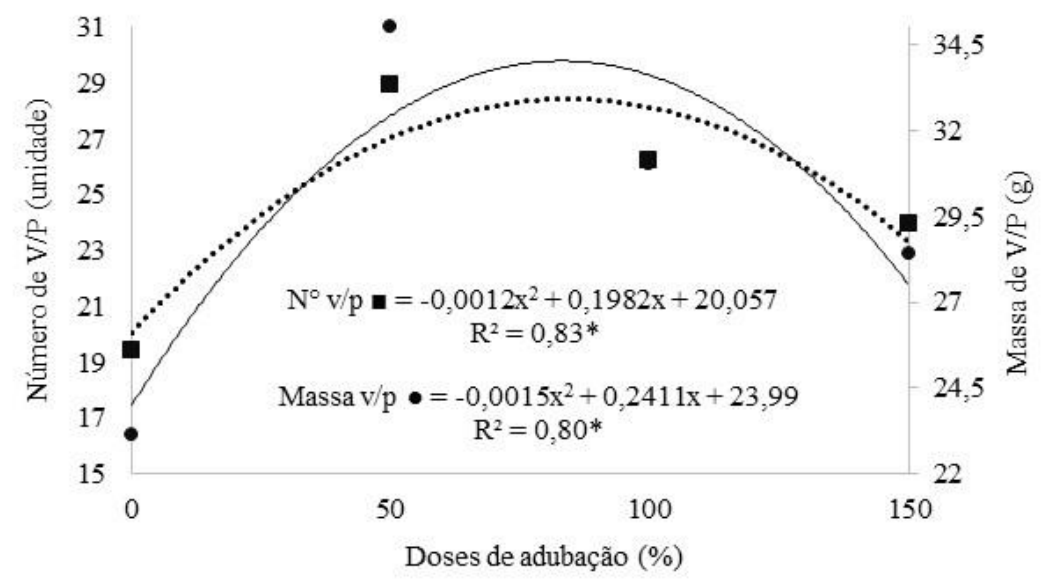

A massa de vagens por planta no sistema de gotejo obtive diferença significativa $(p<0,05)$ em função das doses de adubação, com modelo de regressão polinomial (Figura 3). A máxima massa de $33,68 \mathrm{~g}$ de vagens por planta foi alcançado na dose de $80,37 \%$. No trabalho realizado por Sousa (2013), a dose de potássio que proporcionou a maximização da massa de vagem da cultura do amendoim foi estimada em $62 \mathrm{~kg} \mathrm{ha}^{-1}$ de $\mathrm{K}_{2} \mathrm{O}$, diferindo da melhor dose avaliada no presente trabalho.
No fator adubação (Tabela 4) não ocorreu diferença significativa para todas as variáveis analisadas. Souza et al. (2012) ao estudarem os efeitos das doses de fósforo, obtiveram resultados diferentes aos desse trabalho, a massa de 100 grãos apresentou significância $(p<0,05)$ com o aumento das doses de fósforo de 50, $100 \mathrm{e}$ $200 \mathrm{~kg} \mathrm{ha}^{-1}$ de $\mathrm{P}_{2} \mathrm{O}_{5}$, proporcionando aumento de $5 \%$ para a maior dose estudada em relação à não aplicação do fósforo. 
Tabela 4. Síntese da análise de variância, análise de regressão e do teste de médias para as variáveis Massa de grãos por vagens (MG/V), Massa de mil grãos (M1000G) e massa de cem vagens (M100V).

\begin{tabular}{|c|c|c|c|c|c|c|c|}
\hline \multicolumn{8}{|c|}{ Valores de F } \\
\hline \multirow{2}{*}{ Fontes de Variação } & \multicolumn{3}{|c|}{ MG/V } & \multicolumn{2}{|c|}{ M1000G } & \multicolumn{2}{|c|}{ M100V } \\
\hline & GL & Sequeiro & Gotejo & Sequeiro & Gotejo & Sequeiro & Gotejo \\
\hline Bloco & 3 & $2,47^{\mathrm{ns}}$ & $2,45^{\mathrm{ns}}$ & $1,28^{\mathrm{ns}}$ & $1,07^{\mathrm{ns}}$ & $1,69^{\mathrm{ns}}$ & $1,07^{\mathrm{ns}}$ \\
\hline Adubação (A) & 3 & $1.15^{\mathrm{ns}}$ & $3.16^{\mathrm{ns}}$ & $2.10^{\mathrm{ns}}$ & $0.68^{\mathrm{ns}}$ & $3.27^{\mathrm{ns}}$ & $0.68^{n s}$ \\
\hline Resíduo 1 & 9 & - & - & - & - & - & - \\
\hline Espaçamento (E) & 1 & $1.54^{\mathrm{ns}}$ & $4.28^{\mathrm{ns}}$ & $0.92^{\mathrm{ns}}$ & $2.61^{\mathrm{ns}}$ & $0.01^{\mathrm{ns}}$ & $2.61^{\mathrm{ns}}$ \\
\hline$A^{*} E$ & 6 & $0.46^{\mathrm{ns}}$ & $2.54^{\mathrm{ns}}$ & $0.78^{\mathrm{ns}}$ & $0.82^{\mathrm{ns}}$ & $0.31^{\mathrm{ns}}$ & $0.82^{\mathrm{ns}}$ \\
\hline Resíduo 2 & 12 & - & - & - & - & - & - \\
\hline CV1 (\%) & - & 56.42 & 31.07 & 22.46 & 31.98 & 19.28 & 31.98 \\
\hline CV2 (\%) & - & 48.69 & 31.35 & 22.05 & 27.89 & 21.57 & 27.89 \\
\hline Média geral & - & 2,86 & 15,40 & 34956,25 & 40515,62 & 87,77 & 40,51 \\
\hline \multicolumn{8}{|c|}{ Análise de Regressão para Adubação } \\
\hline Linear & & $1.78^{\mathrm{ns}}$ & $1.56^{\mathrm{ns}}$ & $0.10^{\mathrm{ns}}$ & $0.47^{\mathrm{ns}}$ & $0.89^{\mathrm{ns}}$ & $0.47^{\mathrm{ns}}$ \\
\hline Quadrática & & $1.40^{\mathrm{ns}}$ & $4.29^{\mathrm{ns}}$ & $2.56^{\mathrm{ns}}$ & $0.46^{\mathrm{ns}}$ & $8.91^{\mathrm{ns}}$ & $0.46^{\mathrm{ns}}$ \\
\hline \multicolumn{8}{|c|}{ Teste de Médias } \\
\hline Espaçamento & & & ----------- & -------------. & ----------------- & -------------- & \\
\hline 10 & & $2.55 \mathrm{a}$ & $13.63 \mathrm{a}$ & 33650,00 a & 37287,50 a & $87.42 \mathrm{a}$ & $37.28 \mathrm{a}$ \\
\hline 20 & & $3.16 \mathrm{a}$ & $17.17 \mathrm{a}$ & $36262,50 \mathrm{a}$ & 43743,75 a & $88.12 \mathrm{a}$ & $43.74 \mathrm{a}$ \\
\hline
\end{tabular}

Nota: Médias seguidas pela mesma letra minúscula na coluna não diferem entre si pelo teste de Tukey a $5 \%$ de probabilidade.**: significativo ( $\mathrm{P}<0,01)$; *: significativo $(\mathrm{P}<0,05)$; ns: não significativo; $\mathrm{CV} \%$ : coeficiente de variação.

Verifica-se que nenhuma das variáveis obtiveram houve diferença significativa para 0 fator espaçamento (Tabela 4), evidenciando que as plantas responderam bem ao adensamento e a competição por água, luz e nutrientes. De acordo com Camara et al. (2018), ao analisar a produtividade de feijão caupi crioulo em função do espaçamento entre linhas e número de plantas por cova relataram que o maior espaçamento apresentar menor competição interespecífica por conta da menor densidade populacional, permitindo 0 melhor aproveitamento de luz, água e nutrientes.

A análise de variância (Tabela 5) demonstrou que não houve interação significativa entre os fatores estudados, nota-se ainda que o fator adubação apresentou maiores coeficientes de variação em relação à os do espaçamento obtendo maior efeito nas variáveis analisadas. 
Tabela 5. Síntese da análise de variância, análise de regressão e do teste de médias para as variáveis Produtividade de vagens (PV), Produtividade de grãos (PG) e Porcentagem de grãos não comerciais (GNC).

\begin{tabular}{|c|c|c|c|c|c|c|c|}
\hline \multicolumn{8}{|c|}{ Valores de F } \\
\hline \multirow{2}{*}{ Fontes de Variação } & \multicolumn{3}{|c|}{ PV } & \multicolumn{2}{|c|}{ PG } & \multicolumn{2}{|c|}{ GNC } \\
\hline & $\mathrm{GL}$ & Sequeiro & Gotejo & Sequeiro & Gotejo & Sequeiro & Gotejo \\
\hline Bloco & 3 & $0,93^{n s}$ & $1,83^{\mathrm{ns}}$ & $1,21^{\mathrm{ns}}$ & $1,07^{\text {ns }}$ & $3,88^{*}$ & $3,51^{\text {ns }}$ \\
\hline Adubação (A) & 3 & $0,41^{\mathrm{ns}}$ & $0,50^{\mathrm{ns}}$ & $0,47^{\mathrm{ns}}$ & $0,33^{n s}$ & $1,12^{\mathrm{ns}}$ & $0,07^{\mathrm{ns}}$ \\
\hline Resíduo 1 & 9 & - & - & - & - & - & - \\
\hline Espaçamento (E) & 1 & $0,03^{n s}$ & $0,20^{n s}$ & $0,77^{\mathrm{ns}}$ & $0,21^{\mathrm{ns}}$ & $0,30^{\mathrm{ns}}$ & $2,70^{\mathrm{ns}}$ \\
\hline$A^{*} E$ & 6 & $0,43^{\mathrm{ns}}$ & $2,86^{\mathrm{ns}}$ & $0,09^{n s}$ & $1,83^{\mathrm{ns}}$ & $1,81^{\mathrm{ns}}$ & $2,11^{\mathrm{ns}}$ \\
\hline Resíduo 2 & 12 & - & - & - & - & - & - \\
\hline CV1 (\%) & - & 71,88 & 36,12 & 49,99 & 29,58 & 53,10 & 40,35 \\
\hline CV2 (\%) & - & 55,52 & 27,48 & 36,60 & 21,51 & 40,57 & 28,73 \\
\hline Média geral & - & 207,07 & 1159,20 & 738,54 & 2188,54 & 33,48 & 11,47 \\
\hline \multicolumn{8}{|c|}{ Análise de Regressão para Adubação } \\
\hline Linear & & $0,00^{\text {ns }}$ & $1,40^{\mathrm{ns}}$ & $0,27^{\mathrm{ns}}$ & $0,88^{\mathrm{ns}}$ & $0,87^{\mathrm{ns}}$ & $0,11^{\mathrm{ns}}$ \\
\hline Quadrática & & $0,61^{\mathrm{ns}}$ & $0,04^{\mathrm{ns}}$ & $0,59^{\mathrm{ns}}$ & $0,02^{\mathrm{ns}}$ & $1,74^{\mathrm{ns}}$ & $0,07^{\mathrm{ns}}$ \\
\hline \multicolumn{8}{|c|}{ Teste de Médias } \\
\hline Espaçamento & & \multicolumn{4}{|c|}{ 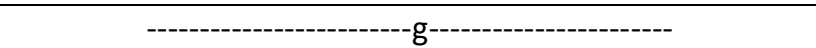 } & \multicolumn{2}{|c|}{-----------\%"--------- } \\
\hline 10 & & $210,38 \mathrm{a}$ & 1184,56 a & $696,52 \mathrm{a}$ & $2226,38 \mathrm{a}$ & $34,2 \mathrm{a}$ & $12,4 \mathrm{a}$ \\
\hline 20 & & $203,76 \mathrm{a}$ & $1133,84 \mathrm{a}$ & $780,55 \mathrm{a}$ & $2150,69 a$ & $32,8 \mathrm{a}$ & $10,5 \mathrm{a}$ \\
\hline
\end{tabular}

Nota: Médias seguidas pela mesma letra minúscula na coluna não diferem entre si pelo teste de Tukey a $5 \%$ de probabilidade.**: significativo ( $\mathrm{P}<0,01)$; $^{*}$ : significativo $(\mathrm{P}<0,05)$; ns: não significativo; $\mathrm{CV} \%$ : coeficiente de variação.

Os fatores adubação e espaçamento não obteve resultados significativos para nem uma das variáveis estudadas. Resultados que diferem dos encontrados por Silveira (2010), ao estudarem o efeito da adubação e densidade populacional observaram que o uso de 15 plantas por metro linear aumenta a produção de vagens por hectare, porém a produção por planta é reduzida o que encarece o plantio e inviabiliza essa densidade.

Os resultados obtidos nesse trabalho diferem dos resultados encontrados por Peixoto et al. (2008), que constataram o aumento do volume de vagens com redução do espaçamento entre plantas com densidade de 10 plantas $\mathrm{m}^{-1}$, ao verificarem que o espaçamento de $10 \mathrm{~cm}$ entre plantas apresentou os melhores resultados.

Observa-se que o uso da irrigação proporcionou um maior resultado para a produtividade de vagens quando comparado com o sistema de sequeiro (Tabela 5), nota-se ainda que as variáveis produtividade de grãos e percentagem de grãos não comerciais em sequeiro foram maiores que as observadas no sistema de gotejo, isso ocorre devido a planta está passando por um estresse hídrico, a mesma direciona a produção de fotoassimilados para a reprodução, com intuito de perpetuar a espécie, produzindo grandes quantidades de sementes, essas sementes muitas vezes são inviáveis para a reprodução e comércio uma vez que não ocorre o seu devido desenvolvimento e maturação.

De acordo com Ferrari Neto et al. (2012) - estresse hídrico interfere diretamente na frutificação, resultando na formação de grãos com menor peso específico, ou até mesmo o não preenchimento dos grãos, diminuindo a quantidade de grãos destinados a comercialização.

\section{Conclusão}

A adubação de $80 \%$ da dose recomendada de fósforo e potássio foi suficiente para suprir as necessidades da cultura.

O espaçamento de $10 \mathrm{~cm}$ entre plantas é mais recomendado para a cultura do amendoim, proporcionando valores de número de vagens por planta, massa de vagens por planta, massa de grãos por planta e produtividade grãos similares ao espaçamento de $20 \mathrm{~cm}$.

$\mathrm{O}$ uso de irrigação complementar em anos com baixa precipitação atmosférica é excelente alternativa para elevar a produtividade de vagens em mais de $550 \%$ e de grãos da cultura do amendoim em mais $250 \%$. 


\section{Referências}

ALVARES, C. A.; STAPE, J. L.; SENTELHAS, P. C.; GONÇALVES, J. L. M.; SPAROVEK, G. Koöppen's climate classification map for Brazil. Meteorologische Zeitschrift, Berlim, v.22, n.6, p.711-728, 2013. https://doi.org/10.1127/09412948/2013/0507

ARTUR, A. G.; OLIVEIRA, D. P.; COSTA, M. C. G.; ROMERO, R. E.; SILVA, M. V. C.; FERREIRA, T. O. Variabilidade espacial dos atributos químicos do solo, associada ao microrrelevo. Revista Brasileira de Engenharia Agrícola e Ambiental, Campina Grande, v.18, n.2, p.141-149, 2014. https://doi.org/10.1590/S1415-

43662014000200003

ASSUNÇÃO, H. F.; ESCOBERDO, J. F. Estimativa da exigência hídrica do amendoim usando um modelo agrometeorológico. Irriga, Botucatu, v.14, n.3, p.325-335, 2009. https://doi.org/10.15809/irriga.2009v14n3p325$\underline{335}$

CAMARA, F. T.; MOTA, A. M. D.; NICOLAU, F. E. A.; PINTO, A. A.; SILVA, J. M. F. Produtividade de feijão caupi crioulo em função do espaçamento entre linhas e número de plantas por cova. Revista de Agricultura Neotropical, Cassilândia, v.5, n.2, p.19-24, 2018. https://doi.org/10.32404/rean.v5i2.2282

CONAB. Acompanhamento da safra brasileira de grãos. Disponível em: https://www.conab.gov.br/component/k2/item/ download/27148 784c4 d4368c35979df1ea007136999ae. Acesso em: 29 jul. 2019.

COSTA, T. B.; SILVA, F. E.; PENHA FILHO, N.; LOPES, N. S.; CAMARA, F. T. Resposta à adubação de duas cultivares de amendoim em dois sistemas de semeadura. Agrarian Academy, Goiânia, v.4, n.8, p.240-248, 2017. https://doi.org/10.18677/Agrarian Academy 20 $\underline{17 b 25}$

EMBRAPA. Sistema de produção de amendoim: fertilidade do solo e adubação. Campinas Grande: Embrapa Algodão, 2014. Disponível em: https://www.spo.cnptia.embrapa.br/conteudo?p _p_lifecycle=0\&p_p_id=conteúdoportlet_WAR_si stemasdeproducaolf6_1ga1ceportlet\&p_p_col_c ount $=1 \& p \_p \_c o l i d=$ column\&p_p_state $=$ normal
\&p_r_p_76293187_sistemaProducaold=3803\&p_ r_p_996514994_topicold=3432\&p_p_mode=view . Acesso em: 01 maio 2019.

FERREIRA, D. F. SISVAR: a computer statistical analysis system. Ciência e Agrotecnologia, Lavras, v. 35 n. 6, p. 1039-1042, 2011.

FERREIRA, T. Aspectos sanitários da cultura do amendoim. Revista Eletrônica de Biologia, Monte Alegre, v.7, p.301-320, 2014.

https://doi.org/10.1590/S1413-

$\underline{70542011000600001}$

FUNCEME. Levantamento de reconhecimento de média intensidade dos solos da Mesoregião do Sul Cearense. Fortaleza, 2012. Disponível em: https://trove.nla.gov.au/version/238870832.

Acesso em: 24 abr. 2019.

GOMES, F. G. Curso de estatística experimental. 15. ed. Piracicaba: FEALQ, 2009. 451p.

GRANT, C. A.; FLATEN, D. N.; TOMASIEWICZ D. J.; SHEPPARD, S. C.; A Importância do fósforo no desenvolvimento inicial da planta. Informações Agronômicas, Piracicaba, ed. 95, p.1-5, 2001.

HEID, D. M.; ZÁRATE, N. A. H.; OHLAND, R. A. A.; TORALES, E. P.; MORENO, L. B.; VIEIRA, M. C. Produtividade agronômica de genótipos de amendoim Virginia cultivados com diferentes espaçamentos entre fileiras no canteiro. Revista de Ciências Agrárias, Lisboa, v.39, n.1, p.105-113, 2016. https://doi.org/10.19084/RCA15058

HESS, L. Potássio com aminoácidos melhora o enchimento da cebola. Campo \& Negócios, Uberlândia, ed. 116, 2015.

MARQUES, D. J; BIANCHINI, H. C.; ROEWER L. A.; Fosfito de potássio contribui para enchimento de grãos. Campo \& Negócios, Uberlândia, ed. 141, 2014

FERRARI NETO, J.; DA COSTA, C. H. M.; CASTRO, G. S. A. Ecofisiologia do amendoim. Scientia Agraria Paranaensis, v.11, n.4, p.1-13, 2012. https://doi.org/10.18188/1983-

1471/sap.v11n4p1-13

PEIXOTO, C. P.; GONCALVES, J. A.; PEIXOTO, M. F. S. P.; CARMO, D. O. Características agronômicas e produtividade de amendoim em diferentes 
espaçamentos e épocas semeadura no Recôncavo Baiano. Bragantia, Campinas, v.67, n.3, p.563-568, 2008. https://doi.org/10.1590/S000687052008000300016

SANTOS, R. C.; FREIRE, R. M. M; LIMA, L. M.; ZAGONEL, G. F.; COSTA, B. J. Produtividade de grãos e óleo de genótipos de amendoim para o mercado olequímico. Revista Ciência Agronômica. Fortaleza, v.43, n.1, p.72-77, 2012. https://doi.org/10.1590/S1806$\underline{66902012000100009}$

SANTOS, R. C.; CUSTÓDIO, R. J. M.; SANTOS, V. P. Eficiência reprodutiva em genótipos de amendoim e correlação fenotípica entre caracteres ligados ao ginóforo. Ciência e Agrotecnologia, Lavras, v.24, n.3, p.617-622, 2000.

SILVEIRA, P. S.; PEIXOTO, C. P.; PASSOS, A. R.; SILVEIRA, T. S. Produtividade do amendoim em diferentes épocas de semeadura e com diferentes densidades de plantas no recôncavo sul baiano. Revista Brasileira Oleaginosas e Fibrosas, Campina Grande, v.14, n.3, p.115 - 123, 2010.

SILVEIRA, P. S.; PEIXOTO, C. P.; LEDO, C. A. S.; PASSOS, A. R.; BLOISI, A. M.; BORGES, V. P. Componentes de produção de amendoim em diferentes épocas de semeadura e densidades de plantas. Magistra, Cruz das Almas, v.25, n.3, p.182-190, 2013.

SOUSA, G. G.; AZEVEDO, B. M.; OLIVEIRA, J. R.R.; MESQUITA, T. O.; VIANA, T. V. A.; Ó, L.M.G. Adubação potássica aplicada por fertirrigação e pelo método convencional na cultura do amendoim. Revista Brasileira de Engenharia Agrícola e Ambiental, Campina Grande, v.17, n.10, p.1055-1060, 2013. https://doi.org/10.1590/S141543662013001000005

SOUZA, U. O.; SANTOS, L. G.; CARVALHO, G. B.; SANTOS, A. R.; SOUZA, G. S. Adubação fosfatada e qualidade de luz modificada no desenvolvimento e produtividade da cultura do amendoim. Enciclopédia Biosfera, Goiânia, v.8, n.15, p. 1635, 2012.
TASSO JUNIOR, L. C.; MARQUES, M. O.; NOGUEIRA, G. A. A cultura do amendoim. Jaboticabal, 2004. 220p. 